\title{
Radicaal anders: waarom semencryopreservatie bij mannen met een testistumor moet worden aangeboden vóór de radicale orchiëctomie
}

\author{
Marij Dinkelman-Smit ${ }^{1} \cdot$ Willem P. A. Boellaard $^{1} \cdot$ Everlien R. Timmer $^{1} \cdot$ Niels J. van Casteren $^{2}$. \\ Gert R. Dohle ${ }^{1}$
}

Published online: 28 July 2016

(C) The Author(s) 2016. This article is available at SpringerLink with Open Access.

Samenvatting Semencryopreservatie is een algemeen geaccepteerde methode om kinderwens in de toekomst mogelijk te maken voor mannen die door gonadotoxische chemoof radiotherapeutische behandeling onvruchtbaar dreigen te worden. In een retrospectief onderzoek in een cohort van 604 mannen met een maligne testistumor, toonden wij aan dat bij een op de zes patiënten semencryopreservatie niet mogelijk of suboptimaal was in verband met azoöspermie, aspermie of cryptozoöspermie. Bij deze patiënten kan testiculaire sperma-extractie (TESE) een alternatieve methode van fertiliteitspreservatie zijn. TESE kan tijdens de radicale orchiëctomie plaatsvinden uit niet-aangedaan testisparenchym dat naast de testistumor is gelegen, of uit de contralaterale testis. In dit artikel dragen wij argumenten aan voor semencryopreservatie bij patiënten met testistumoren vóór de radicale orchiëctomie.

Trefwoorden maligne kiemceltumor - maligne testistumor · semencryopreservatie · azoöspermie · TESE · fertiliteit

\section{Radically different: why sperm cryopreservation in men with testicular cancer should be offered prior to radical orchiectomy}

Abstract Sperm cryopreservation before the onset of oncological treatment is a generally accepted method to preserve

\footnotetext{
dr. Marij Dinkelman-Smit

m.smit.3@erasmusmc.nl

Urologie, Erasmus MC Rotterdam, Rotterdam, Nederland

2 Urologie, IJsselland Ziekenhuis Rotterdam, Rotterdam, Nederland
}

fertility in men with cancer that enables couples to embark on assisted reproduction. In 604 patients with testicular cancer, we retrospectively showed that sperm cryopreservation was unsuccessful in one out of six patients because of azoospermia, aspermia or cryptozospermia. In these patients, testicular sperm extraction (TESE) can be an alternative sperm preservation method. TESE can be performed during radical orchiectomy in normal testicular parenchyma adjacent to the testicular tumor or in the contralateral testis. We provide arguments for sperm preservation strategies in patients with testicular cancer before radical orchiectomy.

Keywords sperm cryopreservation - testicular cancer · azoospermia $\cdot$ TESE $\cdot$ male infertility

\section{Introductie}

Semencryopreservatie is een algemeen geaccepteerde methode om kinderwens in de toekomst mogelijk te maken voor mannen die onvruchtbaar dreigen te worden [1]. Semencryopreservatie wordt doorgaans aangeboden voor de aanvang van gonadotoxische chemo- of radiotherapeutische behandelingen.

In het Erasmus MC wordt sinds 1983 semencryopreservatie aangeboden bij oncologische patiënten. Wij toonden eerder aan dat bij 7,5\% van de verwezen patiënten een azoöspermie wordt geconstateerd, waardoor semencryopreservatie niet mogelijk is [2]. De zaadkwaliteit bij cryopreservatie is significant lager bij mannen met een testiscarcinoom dan bij mannen met andere maligniteiten [2]. Pre-existente verminderde fertiliteit bij mannen met maligne kiemceltumoren zijn, net als cryptorchisme, testiculaire microcalcificaties en testisatrofie, geassocieerd met de 
pathogenese van kiemceltumoren. Dit spectrum wordt omschreven als het testicular dysgenesis syndrome [3].

Bij ongeveer de helft van de patiënten met een niet-obstructieve azoöspermie, kan door middel van testiculaire sperma-extractie (TESE) testiculaire zaadcellen verkregen worden. Sinds 2007 wordt in het Erasmus MC TESE toegepast om chirurgisch testiculaire zaadcellen te verkrijgen bij mannen met onvervulde kinderwens en een niet-obstructieve azoöspermie. Daarnaast wordt TESE incidenteel toegepast om de toekomstige kinderwens veilig te stellen bij patiënten met een azoöspermie bij de poging tot semencryopreservatie. Sinds oktober 2014 is intracytoplasmatische sperma-injectie (ICSI) met chirurgisch verkregen testiculaire zaadcellen buiten studieverband toegestaan in Nederlandse centra die voldoen aan de kwaliteitsnorm 'geassisteerde voortplanting met chirurgisch verkregen zaadcellen' (www.nvog-documenten.nl, kwaliteitsnormen).

Het doel van dit onderzoek is vast te stellen hoe vaak azoöspermie voorkomt bij mannen met een testistumor die semencryopreservatie krijgen aangeboden. Wij voerden dit retrospectieve onderzoek uit om argumenten te verzamelen voor de stelling dat TESE als alternatieve methode van semenpreservatie gemeengoed moet worden in de denkwijze van de uroloog die mannen met testiscarcinoom behandelt.

\section{Materiaal}

Het cohort bestond uit patiënten met een kiemceltumor die tussen 1 januari 1983 en 9 april 2015 een poging semencryopreservatie in het Erasmus MC ondergingen. Klinische gegevens en tumorkarakteristieken werden aangevuld uit het elektronisch patiëntendossier en opgenomen in een SPSS-database (versie 15.0). Resultaten van 854 semencryopreservatieanalyses van 604 mannen met testiscarcinoom, waren beschikbaar voor analyse.

Non-seminoma testis, seminoom en gemengde kiemceltumoren kwamen voor bij respectievelijk $60 \%$, $32 \%$ en $8 \%$ van de patiënten. Bij acht van de 604 patiënten was sprake van een synchrone bilaterale testistumor $(1,3 \%)$. Bij 4,6\% van de patiënten werd een tweede, contralaterale metachrone testistumor gediagnosticeerd. Bij 132 mannen $(21,8 \%)$ vond de poging tot semencryopreservatie plaats voor de radicale orchiëctomie, de overige 436 patiënten werden verwezen voor semencryopreservatie na de radicale orchiëctomie.

\section{Resultaten}

Semencryopreservatie was niet mogelijk bij 77/604 patiënten $(12,8 \%)$. Bij 10,8\% van de eerste pogingen werd een azoöspermie geconstateerd, 2,0\% van de patiënten slaagde er niet in een ejaculaat te produceren (aspermie). De parameters van het semen van 253 van de 604 patiënten $(41,9 \%$ ) voldeed aan de referentiewaarden van de WHO uit 2010. Bij 7,6\% van de patiënten was sprake van een cryptozoöspermie, die wordt gedefinieerd als een zaadcelconcentratie minder dan 1 miljoen per milliliter (tab. 1).

Bij 31 van de 65 patiënten met een azoöspermie was het histologisch verslag beschikbaar van de radicale orchiëctomie, met vermelding van de tumordiameter. De mediane diameter van de testistumor bedroeg $3 \mathrm{~cm}$ (range: 0,04-10). In $16 / 31$ gevallen $(51,6 \%)$ was de tumordiameter minder dan $4 \mathrm{~cm}$.

13 patiënten met een azoöspermie bij de eerste poging tot semencryopreservatie, leverden een tweede ejaculaat in voor analyse, ten minste één dag na de vorige poging. Bij vier patiënten $(30,7 \%)$ vond bij de tweede poging alsnog succesvol semencryopreservatie plaats.

In een subgroep van patiënten met een unilaterale testistumor werden het ejaculaatvolume, de zaadcelconcentratie en progressieve motiliteit vergeleken tussen vóór en ná radicale orchiëctomie. In deze groep werden met de independent samples $t$-test geen significante verschillen gezien in zaadcelkwaliteit (tab. 2).

Tabel 1 Resultaten van semencryopreservatie van 604 mannen met testiscarcinoom.

\begin{tabular}{ll}
\hline & aantal patiënten $(\%)$ \\
\hline azoöspermie & $65(10,8)$ \\
aspermie $^{\mathrm{a}}$ & $12(2,0)$ \\
cryptozoöspermie $^{\mathrm{b}}$ & $46(7,6)$ \\
oligozoöspermie $^{\mathrm{c}}$ & $195(32,3)$ \\
normozoöspermie $^{\mathrm{d}}$ & $253(41,9)$ \\
geen classificatie anders dan 'geschikt' & $33(5,5)$ \\
totaal & 604 \\
\hline
\end{tabular}

${ }^{a}$ Afwezigheid van een ejaculaat

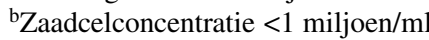

${ }^{\mathrm{c}}$ Zaadcelconcentratie $<15$ miljoen/ml, progressieve motiliteit $(\mathrm{A}+\mathrm{B})$ $\geq 32 \%$

${ }^{\mathrm{d} C}$ Criteria volgens de WHO-Manual [4]

Tabel 2 Parameters semencryopreservatie van patiënten met een unilaterale testistumor, voor en na radicale orchiëctomie en de WHO-referentiewaarden [4].

\begin{tabular}{llll}
\hline & $\begin{array}{l}\text { volume } \\
(\mathrm{ml})\end{array}$ & $\begin{array}{l}\text { concentratie } \\
\left(\mathrm{x} 10^{6}\right)\end{array}$ & $\begin{array}{l}\text { progressieve } \\
\text { motiliteit } \\
(\mathrm{A}+\mathrm{B})(\%)\end{array}$ \\
\hline $\begin{array}{l}\text { WHO-referentiewaarden: } \\
\text { vóór radicale orchiëctomie }\end{array}$ & $>1,5$ & $>15$ & $>32$ \\
$\begin{array}{l}\text { mediaan (IQR) } \\
(n=109)\end{array}$ & 2,4 & 14,0 & 40,0 \\
$\begin{array}{l}\text { ná radicale orchidectomie } \\
\text { mediaan (IQR) }\end{array}$ & $\begin{array}{l}(1,9-4,1) \\
(n=366)\end{array}$ & $(4,1-40,0)$ & $(26,3-50,0)$ \\
\hline
\end{tabular}




\section{Advertisement placed here.}

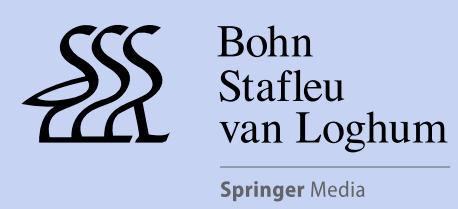

Houten 2016 


\section{Advertisement placed here.}

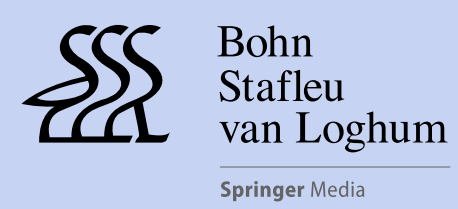

Houten 2016 
Tabel 3 Tumorstadia bij de 604 mannen met testiscarcinoom in de onderzoekspopulatie.

\begin{tabular}{ll}
\hline tumorstadium & $n(\%)$ \\
\hline stadium I & $202(33,4)$ \\
stadium II & $210(34,8)$ \\
stadium III & $17(2,8)$ \\
stadium IV & $64(10,6)$ \\
onbekend & $111(18,4)$ \\
\hline
\end{tabular}

Tabel 4 Therapie die is toegepast bij de 604 mannen met testiscarcinoom in de onderzoekspopulatie.

\begin{tabular}{ll}
\hline therapie & $n(\%)$ \\
\hline chemotherapie & $267(44,2)$ \\
radiotherapie & $110(18,2)$ \\
chemo- en radiotherapie & $22(3,6)$ \\
chemotherapie en/of radiotherapie + RPLKD & $138(22,6)$ \\
surveillance & $67(11,4)$ \\
\hline
\end{tabular}

Tab. 3 en 4 geven een overzicht van de tumorstadia van de onderzoekspopulatie en de behandelmodaliteiten die zijn toegepast.

\section{Discussie}

Dit retrospectieve onderzoek geeft inzicht in de beperkingen van semencryopreservatie bij mannen met een testistumor. Bij ruim $10 \%$ van de patiënten met zaadbalkanker constateerden wij een azoöspermie bij de poging tot het veiligstellen van de toekomstige kinderwens. Daarnaast was bij $7,6 \%$ van de patiënten met een testistumor sprake van een cryptozoöspermie. Geconcludeerd kan worden dat semencryopreservatie in ons cohort bij ruim een op de zes mannen met een testiscarcinoom niet mogelijk of suboptimaal was.

In het voortplantingscentrum in het Erasmus MC worden wij regelmatig geconfronteerd met de hulpvraag van patiënten met een status na radicale orchiëctomie bij wie geen semencryopreservatie is verricht vanwege een azoöspermie. Dit komt zowel voor bij mannen die alleen een radicale orchiëctomie ondergingen, als bij mannen die adjuvant behandeld zijn met chemotherapie. Nu TESE ook in Nederland beschikbaar is, is het opportuun om TESE in te zetten als alternatief voor semencryopreservatie bij azoöspermie om dit soort casuïstiek te voorkomen.

TESE biedt kankerpatiënten met een niet-obstructieve azoöspermie de mogelijkheid de toekomstige kinderwens alsnog veilig te stellen [5]. Testiculaire zaadcellen kunnen uit een testisbiopt worden gecryopreserveerd en bij actieve kinderwens gebruikt worden voor geassisteerde voortplanting door middel van intracytoplasmatische sperma-injectie (ICSI). In onze ervaring, naast wat wordt beschreven in de literatuur [5], is TESE succesvol uitvoerbaar in het radicale orchiëctomiepreparaat, zelfs wanneer er nog maar enkele centimeters normaal testisparenchym aanwezig zijn naast de testistumor. In dit retrospectieve cohortonderzoek toonden wij aan dat de tumordiameter bij meer dan de helft van de patiënten met een azoöspermie kleiner was dan $4 \mathrm{~cm}$. Als TESE niet slaagt in de aangedane testis, of als er onvoldoende normaal testisparenchym aanwezig is, kan tijdens de radicale orchiëctomie TESE verricht worden in de contralaterale testis.

Om fertiliteitspreservatie bij patiënten met een testistumor te optimaliseren, is het van belang om patiënten met een azoöspermie vroegtijdig te identificeren. Het is essentieel om semencryopreservatie aan te bieden vóór de radicale orchiëctomie. In ons onderzoekscohort vond dit slechts bij $21,8 \%$ van de patiënten plaats. Een aanvullend argument om semencryopreservatie te verrichten voor de radicale orchiëctomie, is dat een significant betere zaadkwaliteit voor de ingreep wordt gerapporteerd in de literatuur [6]. Overigens konden wij dit niet bevestigen, waarbij opgemerkt dient te worden dat wij de semenkwaliteit voor of na radicale orchiëctomie vergeleken op groepsniveau en niet individueel. De EAU heeft in haar richtlijn over de behandeling van testiscarcinoom het advies opgenomen de fertiliteitspreservatie bij voorkeur aan te bieden voor de radicale orchiëctomie [7].

De snelle verdubbelingstijd van testistumoren is altijd een argument geweest om de radicale orchiëctomie bij het vermoeden van een testistumor zo snel mogelijk uit te voeren. De Oncoline richtlijn testiscarcinoom uit 2009 stelt dat 'de inguinale orchiëctomie diagnostisch is, en dat deze bij voorkeur zo spoedig mogelijk, doch zeker binnen 2-3 dagen dient te worden uitgevoerd, tenzij er op het moment van diagnose al aanwijzingen zijn voor metastasen [8]. In dat geval bestaat de kans dat de ziekte snel verslechtert, en dient de orchiëctomie met PA-onderzoek bij voorkeur binnen 24 uur te worden uitgevoerd.' Tegenwoordig wordt 75-80\% van de patiënten met een seminomatestis en ongeveer $55 \%$ van de patiënten met een non-seminomatestis gediagnosticeerd met een stadium I-ziekte [7]. Bij deze patiënten is dus 48-72 uur beschikbaar om semencryopreservatie te verrichten voor de radicale orchiëctomie. Stadiëring door middel van tumormarkeronderzoek en CT-onderzoek van de thorax en het abdomen wordt in Nederlandse ziekenhuizen doorgaans uitgevoerd op de dag van diagnose. Het diagnosticeren van patiënten met hoogrisicoziekte, die direct voor chemotherapie in aanmerking komen, wordt daardoor ondervangen.

In alle opleidingsregio's is voldoende mogelijkheid om semencryopreservatie logistiek aan te bieden binnen 48 uur na diagnose, voorafgaand aan de ingreep. Bij uitzondering zou desnoods overwogen kunnen worden semenanalyse te laten verrichten in het eigen ziekenhuis, om in ieder geval azoöspermie uit te sluiten. Als we de bevindingen van deze 
studie extrapoleren naar het aantal nieuwe gevallen van testiscarcinoom in Nederland, per jaar $(n=770)$, zou het jaarlijks gaan om ongeveer 77 patiënten met een azoöspermie ten tijde van de eerste poging tot semencryopreservatie. Op grond van deze getallen zijn wij van mening dat het logistiek haalbaar is om bij patiënten met een azoöspermie de radicale orchiëctomie in combinatie met TESE binnen 72 uur na diagnose plaats te laten vinden in centra waar TESE mogelijk is.

Dit onderzoek is retrospectief en kent daardoor tekortkomingen. Bovendien is het evident dat ons cohort bestaat uit patiënten die veelal voor gonadotoxische behandeling semencryopreservatie kregen aangeboden. Stadium I-ziekte stelden wij vast bij 'slechts' $33,4 \%$ van de patiënten in deze studie. Ruim $70 \%$ van de patiënten werd behandeld met chemotherapie, al dan niet in combinatie met radiotherapie en/of retroperitoneale klierdissectie. Mogelijk is het percentage testiscarcinoom met een non-obstructieve azoöspermie in de praktijk lager dan $10 \%$ wanneer semencryopreservatie wordt aangeboden aan niet-geselecteerde patiënten met testistumoren.

Een tegenargument om bij alle patiënten met testiscarcinoom voor de inguïnale orchiëctomie semencryopreservatie te verrichten, is dat het gebruik van cryosemen laag is en de kosteneffectiviteit daarmee ook. Literatuur laat wisselend gebruik zien, wij toonden eerder aan dat slechts 7,5\% van overlevenden van kanker daadwerkelijk gebruikmakt van het gecryopreserveerde semen voor geassisteerde voortplanting [9]. Mogelijk wordt dit verklaard door herstel van de spermatogenese enerzijds en de lagere kwaliteit van leven van ex-kankerpatiënten, waarin een kinderwens geen rol speelt, anderzijds. Benadrukt moet worden dat dit percentage voortkomt uit onderzoek onder patiënten met uiteenlopende maligniteiten. Daarnaast kan als tegenargument ingebracht worden dat juist aan mannen met azoöspermie voorafgaand aan de chemotherapie de kans moet worden geboden om tijdens radicale orchiëctomie zaadcellen te preserveren door middel van TESE. Deze mannen zullen bij toekomstige kinderwens altijd gebruik moeten maken van TESE-materiaal. Door bij de radicale orchiëctomie naast de testistumor gelegen, normaal testisparenchym te benutten voor TESE, voorkomen wij vervolgoperaties in de contralaterale testis bij die patiënten. Succesvolle TESE bij postchemotherapeutische azoöspermie wordt beschreven $[10,11]$, maar de kans van slagen is beperkt. Bovendien wordt het veiliger geacht nageslacht door middel van geassisteerde voortplanting tot stand te brengen met zaadcellen die geoogst zijn vóór de gonadotoxische behandelingen. De kans om testiculaire zaadcellen te cryopreserveren tijdens de radicale orchiëctomie bespaart patiënten met een azoöspermie teleurstelling en onzekerheid. Onze ervaring is dat patiënten bij wie TESE ten tijde van de radicale orchiëctomie niet succesvol was, beter kunnen berusten in het feit dat hun kinderwens onvervuld blijft dan patiënten met azoöspermie na de chemotherapie bij wie geen semencryopreservatie of TESE is verricht voorafgaand aan de gonadotoxische behandeling.

Deze studie laat zien dat het advies in richtlijnen om semencryopreservatie aan te bieden voor de radicale orchiëctomie, niet goed wordt nageleefd. Wij toonden eerder aan dat dit ook geldt voor het op indicatie afnemen van contralaterale testisbiopten tijdens de radicale orchiëctomie [9]. De risicofactoren voor azoöspermie - testisatrofie, cryptorchisme, infertiliteit en testistumor in de voorgeschiedenis - en een contralaterale testistumor overlappen elkaar. Dit heeft tot gevolg dat het risico op een contralaterale tumor bij patiënten met een azoöspermie verhoogd is. Ook toonden wij aan dat germ cell neoplasia in situ (GCNIS) voorkomt bij $57 \%$ van de patiënten met niet-obstructieve azoöspermie en een contralaterale testistumor in de voorgeschiedenis [12]. Dit kan als extra argument dienen om de internationale richtlijnen te volgen en semencryopreservatie aan te bieden vóór de radicale orchiëctomie, om patiënten die risico lopen op contralaterale GCNIS of een bilaterale of contralaterale testistumor, maximale fertiliteitspreservatie te bieden.

\section{Conclusie}

In een retrospectief onderzoek in een cohort van 604 mannen met een maligne testistumor, toonden wij aan dat bij een op de zes patiënten semencryopreservatie niet mogelijk of suboptimaal was in verband met azoöspermie, aspermie of cryptozoöspermie. Bij deze patiënten kan testiculaire sperma-extractie (TESE) een alternatieve methode van fertiliteitspreservatie zijn. TESE kan tijdens de radicale orchiëctomie plaatsvinden uit niet-aangedaan testisparenchym dat naast de testistumor is gelegen, of uit de contralaterale testis. Om fertiliteitspreservatie bij patiënten met een testistumor te optimaliseren, is het van belang om azoöspermie te diagnosticeren voor de radicale orchiectomie. Dit wordt ondervangen door de europese richtlijn te volgen en semencryopreservatie aan te bieden vóór de radicale orchiëctomie.

Open Access This article is distributed under the terms of the Creative Commons Attribution 4.0 International License (http:// creativecommons.org/licenses/by/4.0/), which permits unrestricted use, distribution, and reproduction in any medium, provided you give appropriate credit to the original author(s) and the source, provide a link to the Creative Commons license, and indicate if changes were made. 


\section{Literatuur}

1. Nangia AK, Krieg SA, Kim SS. Clinical guidelines for sperm cryopreservation in cancer patients. Fertil Steril. 2013;100(5): 1203-9.

2. Casteren NJ van, Boellaard WP, Romijn JC, Dohle GR. Gonadal dysfunction in male cancer patients before cytotoxic treatment. Int J Androl. 2010;33(1):73-9.

3. Skakkebaek NE, Rajpert-De ME, Main KM. Testicular dysgenesis syndrome: an increasingly common developmental disorder with environmental aspects. Hum Reprod. 2001;16(5):972-8.

4. World Health Organization. WHO laboratory manual for the examination and processing of human semen, Fifth edition. ed. 2010.

5. Berookhim BM, Mulhall JP. Outcomes of operative sperm retrieval strategies for fertility preservation among males scheduled to undergo cancer treatment. Fertil Steril. 2014;101(3):805-11.

6. Rives N, Perdrix A, Hennebicq S, Saias-Magnan J, Melin MC, Berthaut I, et al. The semen quality of 1158 men with testicular cancer at the time of cryopreservation: results of the French National CECOS Network. J Androl. 2012;33(6):1394-401.

7. Albers P, Albrecht W, Algaba F, Bokemeyer C, Cohn-Cedermark G, Fizazi K, et al. EAU guidelines on testicular cancer: 2011 update. Eur Urol. 2011;60(2):304-19.
8. Richtlijn Testiscarcinoom 2009, Oncoline. http://www.oncoline.nl/ testiscarcinoom. Geconsulteerd: Geraadpleegd op 7 juni 2016.

9. Casteren NJ van, Santbrink EJ van, Inzen W van, Romijn JC, Dohle GR. Use rate and assisted reproduction technologies outcome of cryopreserved semen from 629 cancer patients. Fertil Steril. 2008;90(6):2245-50.

10. Hsiao W, Deveci S, Mulhall JP. Outcomes of the management of post-chemotherapy retroperitoneal lymph node dissection-associated anejaculation. BJU Int. 2012;110(8):1196-200.

11. Shiraishi K, Matsuyama H. Microdissection testicular sperm extraction and salvage hormonal treatment in patients with postchemotherapy azoospermia. Urology. 2014;83(1):100-6.

12. Boellaard WPADG, Looijenga LHJ. Kans op testiculair carcinoma in situ in cohort van 204 patienten met niet-obstructieve azoospermie. TvU. 2015;5(4):106-11.

dr. Marij Dinkelman-Smit uroloog/androloog

drs. Willem P.A. Boellaard uroloog/androloog

Everlien R. Timmer medisch student

dr. Niels J. van Casteren uroloog/androloog

dr. Gert R. Dohle uroloog/androloog 